\title{
Natural History of Ascending Aortic Aneurysms (40-50 mm): Impact of Bicuspid Aortic Valves
}

\author{
Tarek Malas $^{1}$, Eric Dumont ${ }^{1}$, Siamak Mohammadi ${ }^{1}$, Pierre Voisine ${ }^{2}$, and François \\ Dagenais $^{3}$ \\ ${ }^{1}$ Quebec Heart and Lung Institute \\ ${ }^{2}$ Affiliation not available \\ ${ }^{3}$ Institut universitaire de cardiologie et de pneumologie de Quebec
}

November 11, 2020

\begin{abstract}
Background: Growth of ascending aortic aneurysms in bicuspid aortic valve (BAV) patients is controversial. Methods: To evaluate the natural history of medically treated ascending aortic aneurysms and the impact of BAV, 572 patients (104 pts $\mathrm{BAV} ; 468 \mathrm{pts}$ with tricuspid aortic valve(TAV) with 40-50mm ascending aortic aneurysms were followed prospectively in a dedicated thoracic aortic clinic. Results: Patients with BAV were younger (BAV: $56.5 \pm 10.6$ vs. TAV: $66.9 \pm 9.9 ; \mathrm{p}<0.0001)$ and less high blood pressure (BAV:54.4\% vs. TAV:69.2\%; $\mathrm{p}=0.01$ ). Maximal ascending aortic diameter was significantly larger in BAV vs. TAV patients ( $46.5 \pm 2.3$ vs. $45.2 \pm 3.0 ; \mathrm{p}<0.0001)$. Mean follow-up was $3.9 \pm 2.5$ years. Significantly more patients were operated during follow-up for the ascending aorta or the aortic valve in the BAV group (BAV:32.7\% vs. TAV:7.3\%; p<0.0001). Only one patient with TAV was operated emergently for an acute aortic syndrome. Operative mortality was $0 \%$ and overall mortality was $10.3 \%$. Five- and ten-year freedom from ascending aortic aneurysm progression $>2$ mm was comparable for both groups BAV vs. TAV ( $86.5 \%$ vs. $83.9 \%)$ and $(36.0 \%$ vs. $29.4 \%)$; (log rank=0.51). Five- and ten-year survival for both groups was BAV vs TAV (96.7\% vs $96.6 \%)$ and $(91.2 \%$ vs $90.8 \%)$ years $(\mathrm{p}=0.94)$. Conclusions: Medically treated $40-50 \mathrm{~mm}$ ascending aortic aneurysms show slow growth rate comparable for BAV and TAV patients. Freedom from acute aortic-related events and survival are very high in both BAV and TAV patients.
\end{abstract}

\section{Hosted file}

JCS Final Submission.pdf available at https://authorea.com/users/374749/articles/492198natural-history-of-ascending-aortic-aneurysms-40-50-mm-impact-of-bicuspid-aortic-valves 

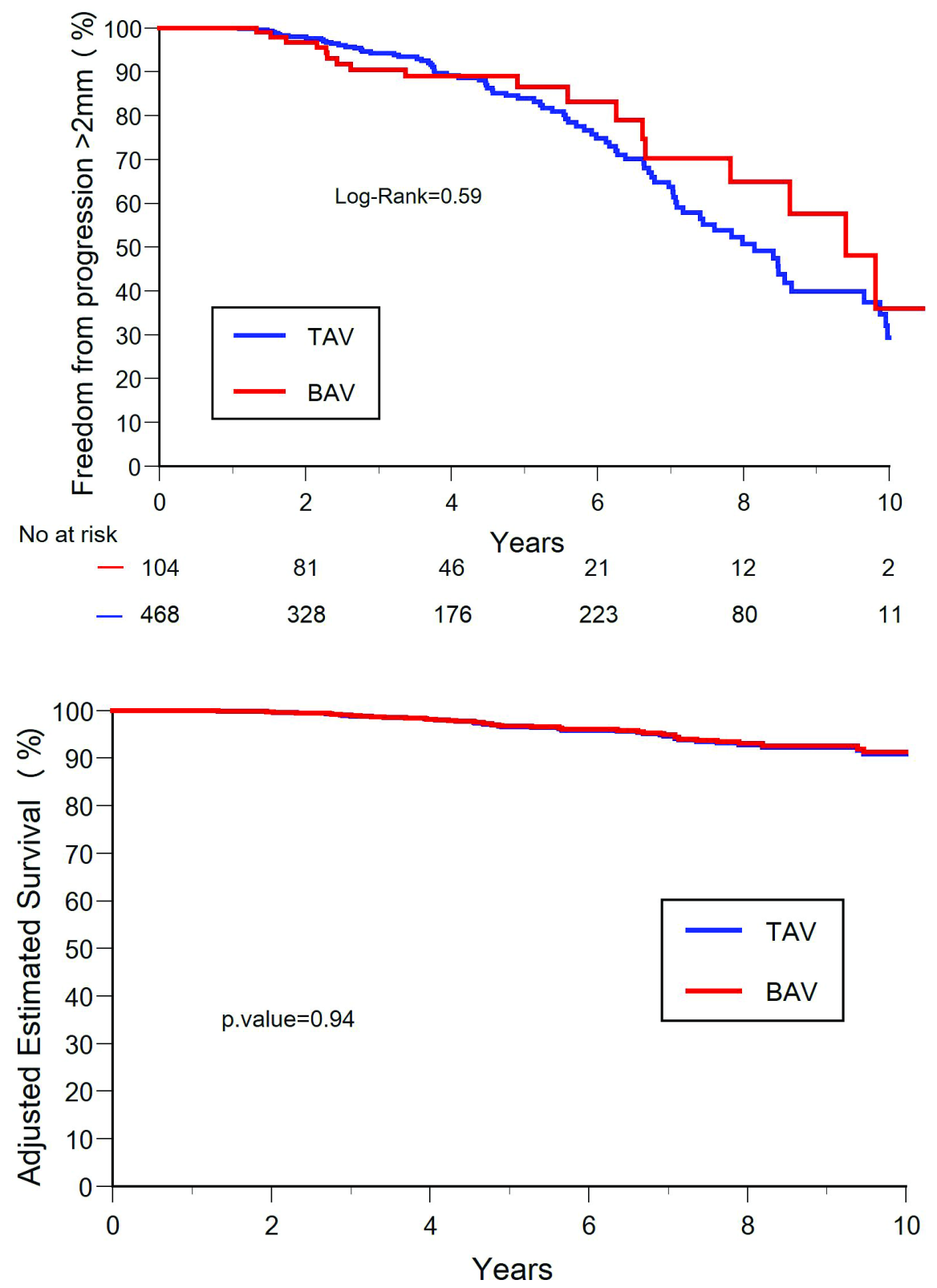

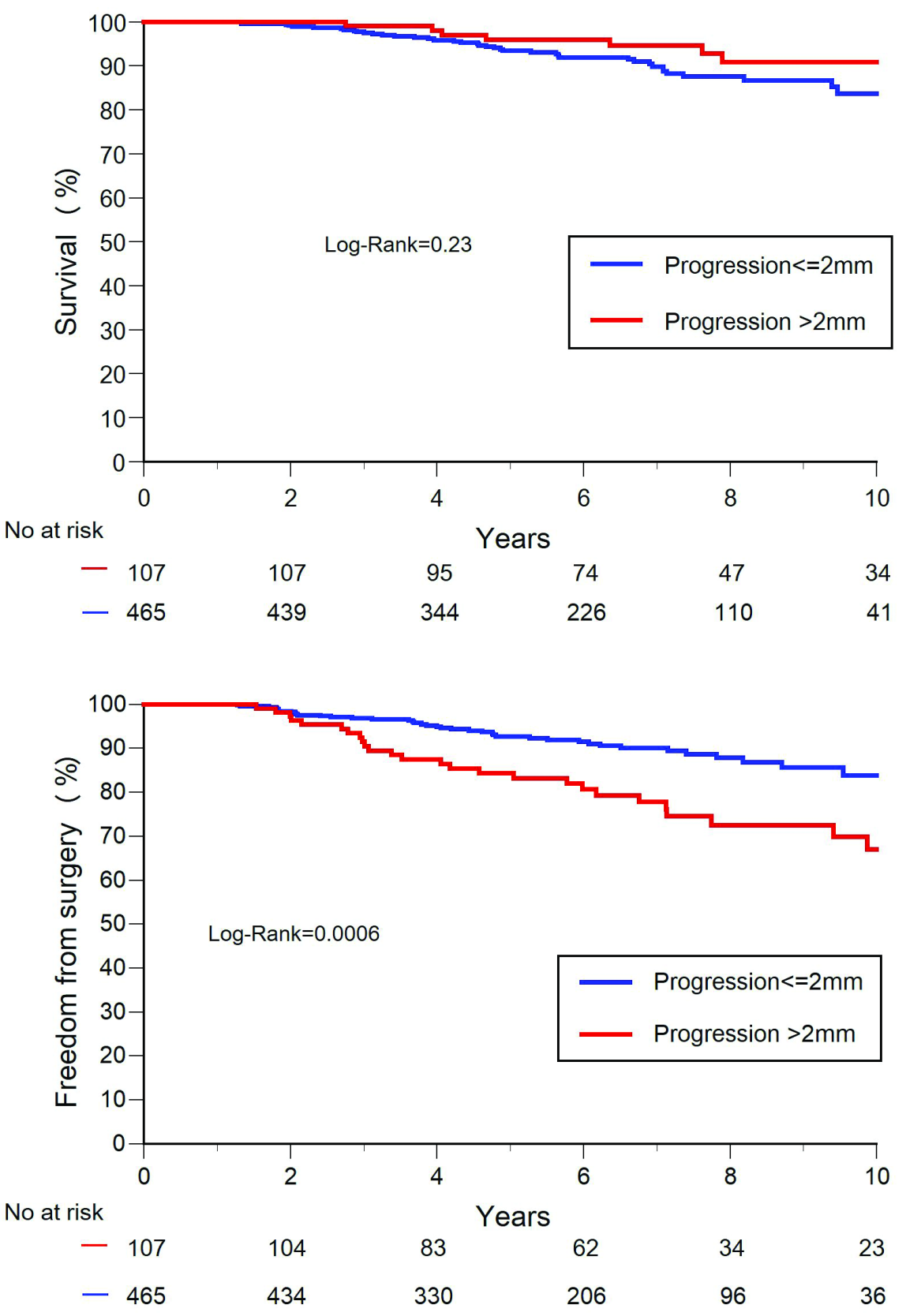

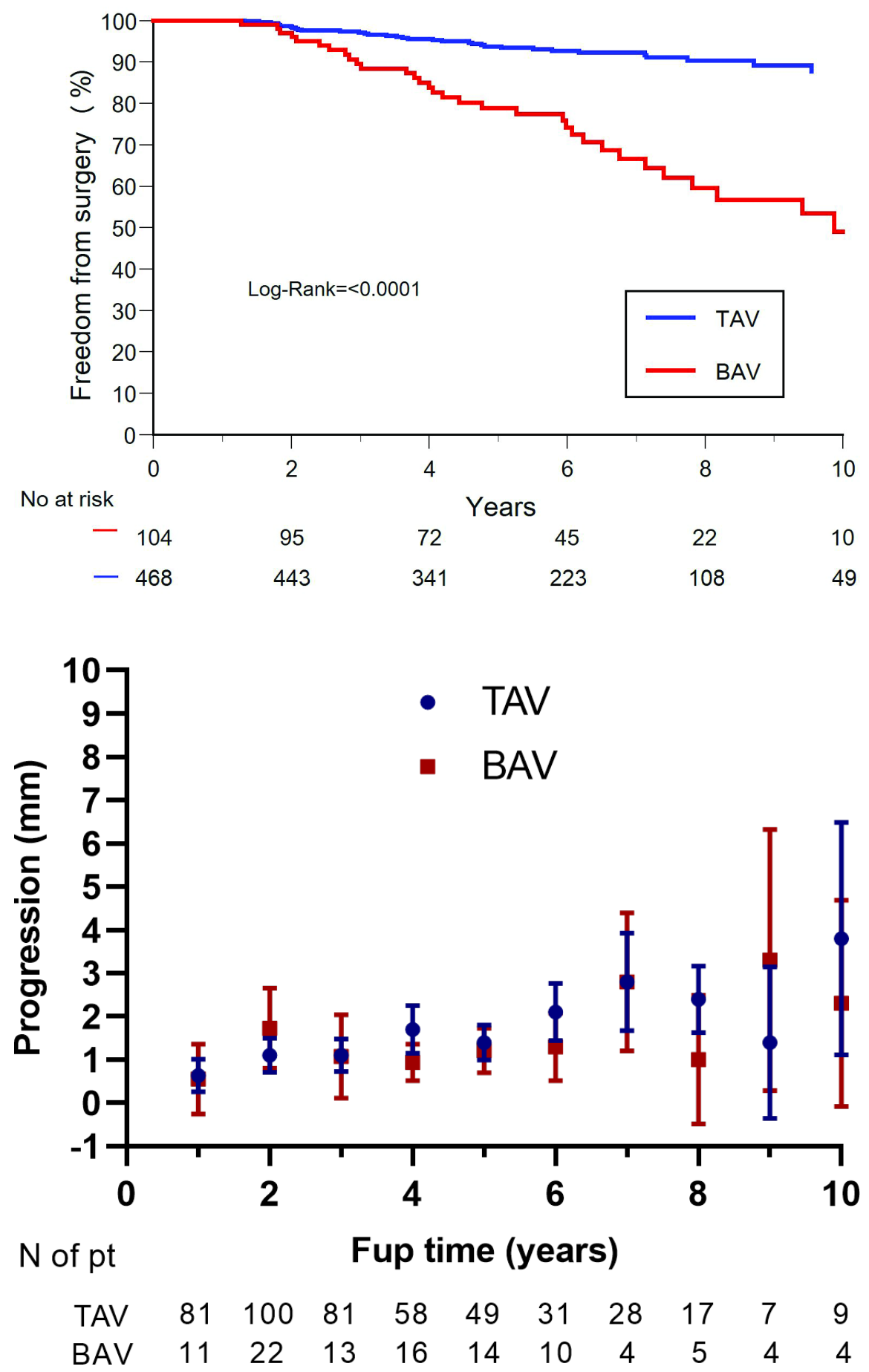